\title{
EENIGE AANVULLINGEN OP DE ENCYCLOPAEDIE VAN NEDERLANDSCH WEST-INDIE
}

DE BELASTINGEN IN CURAÇAO

EOOR

C. R. WEYTINGH

II

\section{A Belastingen}

\section{$15 \mathrm{H}$ ond enbelasting}

Bij de Verordening van 11 April 1923 (P.B. No. 14) werd opnieuw vastgesteld eene Verordening tot heffing eener belasting op het houden van honden in de Kolonie, tevens maatregelen bevattende om den overlast te keer te gaan, die aan de ingezetenen wordt veroorzaakt door honden, zich bevindende op de openbare straten en wegen, zoomede op voor een ieder toegankelijke particuliere erven.

De belasting bedraagt $f 5$.- per jaar voor elken hond gehouden in het stadsdistrict op Curaçao of in de hoofdplaatsen op de eilanden Aruba, Bonaire en St. Martin en $f 3 .-$ per jaar daarbuiten.

Het belastingjaar vangt aan met den 1sten Mei; de belasting is voor de helft verschuldigd voor een hond, die door den houder in de laatste 6 maanden van het belastingjaar is verkregen, terwijl de belasting niet is verschuldigd voor honden, die gehouden worden door personen, die korter dan een maand in de Kolonie verblijf houden.

$\mathrm{Bij}$ de inwerkingtreding van genoemde Verordening op $1 \mathrm{Mei}$ 1923 verviel de Verordening van 31 October 1901 (P.B. 1902 No. 7), zooals gewijzigd, laatstelijk bij die van 22 Augustus 1917 (P.B. 1918 No. 6).

Deze belasting bracht op in:
1912 f 2.067.-
$1926 f$ 6.676.-
1913 1.815.-
1927 7.128.- 


$\begin{array}{llll}1914 & 1.664 .- & 1928 & 7.516 .- \\ 1915 & 1.404 .- & 1929 & 6.721 .- \\ 1916 & 1.443 .- & 1930 & 57.14 .- \\ 1917 & 1.485 .- & 1931 & 3.935 .- \\ 1918 & 2.424 .- & 1932 & 5.299 .- \\ 1919 & 2.260 .- & 1933 & 8.612 .- \\ 1920 & 2.367 .- & 1934 & 8.741 .- \\ 1921 & 2.538 .- & 1935 & 10.424 .- \\ 1922 & 3.034 .- & 1936 & 10.900 .- \\ 1923 & 4.995 .- & 1937 & 10.265 .- \\ 1924 & 5.994 .- & 1938 & 8.578 .- \\ 1925 & 7.784 .- & 1939 & 7.651 .-\end{array}$

16 Motorrijtuig-, rijwiel- en motorbootbelasting

Met ingang van 1 Januari 1929 trad in werking de ,,motorrijtuig-, rijwiel- en motorbootbelastingverordening 1928" (P.B. 1928 No. 77) tot heffing van eene belasting op motorrijtuigen en rijwielen, die op den openbaren weg en op motorbooten, geen zeeschepen zijnde, die op de openbare wateren worden gebruikt.

De belasting bedraagt per jaar:

$a$ voor een motorrijtuig op meer dan drie wielen:

op Curaçao en Aruba $f$ 80.- en op Bonaire f 50.- .

$b$ voor een motorrijtuig op twee of drie wielen $f 20$.-

$c$ voor een rijwiel $f 5$.-

$d$ voor een motorboot $f$ 15.-.

Rijwielen en booten, waarop of waaraan hulpmotoren zijn aangebracht, worden beschouwd als motorrijtuigen en motorbooten.

De belasting wordt geheven door middel van nummerplaten, die tegen betaling van de belasting en van den prijs der platen worden uitgegeven door den Ontvanger.

Ieder nummerplaat is slechts geldig voor het eiland, waarop die is uitgegeven.

De belasting bracht op in

$\begin{array}{llll}1929 & f 172.341 .- & 1934 & f 161.095 .- \\ 1930 & 160.164 .- & 1935 & 204.055 .- \\ 1931 & 165.409 .- & 1936 & 154.013 .- \\ 1932 & 137.308 .- & 1937 & 136.642 .- \\ 1933 & 152.345 & 1938 & 183.403 .- \\ & & 1939 & 217.146 .-\end{array}$


17 Petroleumraffinaderijbelasting

Ten einde eventueele oprichters van een petroleumraffinaderij in Curaçao vooraf met stelligheid zouden kunnen weten welke de fiscale rechten zijn waaraan het bedrijf onderworpen zal zijn en in welken vorm die zullen worden geheven, opdat niet de onzekerheid omtrent dit een en ander een beletsel mocht blijken voor de keuze van Curaçao als zetel van het bedrijf, werd op 5 Mei 1915 vastgesteld de Verordening betreffende de petroleum raffinaderijbelasting (P.B. 1915 No. 46), met bepaling dat de Verordening op 1 Augustus 1915 in werking treedt.

De belasting wordt geheven naar de volgende grondslagen

1. petroleum

2. gasoline.

Onder petroleum wordt in deze Verordening verstaan de na overhaling uit ruwe olie verkregen zuivere olie, die als lampolie gebruikt kan worden.

Onder gasoline dat product der ruwe olie, hetwelk verkregen wordt door distillatie, overgaande alvorens lampolie wordt verkregen, met kookpunt tot 150 graden Celsius.

De belasting bedraagt 80 cent per H.L. petroleum en 40 cent per H.L. gasoline.

Belastingplichtig is hij, die bij den aanvang van het belastingjaar (1 Januari) beheerder der raffinaderij is; de aanslag geschiedt telkens voor één jaar. De aanslagen worden vastgesteld door eene door den Gouverneur te benoemen commissie van 3 leden, waarvan lid en voorzitter is de Inspecteur der Belastingen.

Bezwaren tegen een opgelegde aanslag kunnen ingediend worden bij een Raad van Beroep, die bevoegd is een aanslag op te leggen, afwijkende van dien door de commissie van aanslag vastgesteld.

De belasting is invorderbaar in 4 gelijke termijnen, verschijnende op den voorlaatsten werkdag van elk kalenderkwartaal.

Bij Verordening van 17 Maart 1933 (P.B. No. 50) werd de Verordening van 5 Mei 1915 (P.B. No. 46) zooals gewijzigd bij die van 11 Juli 1917 (P.B. No. 34), ingetrokken; zulks in verband met de heffing van een bijzonder invoerrecht op benzine.

De belasting bracht op in:

$\begin{array}{llll}1919 & f \text { 4.077.- } & 1924 & f 3.418 .- \\ 1920 & 4.425 .- & 1925 & 1.656 .- \\ 1921 & 5.061 .- & 1926 & 4.422 .- \\ 1922 & 4.088 .- & 1927 & 1.346 .- \\ 1923 & 3.511 .- & 1928 & 2.454 .-\end{array}$




\section{B Heffingen}

$1 \mathrm{Schoolgelden}$

Bij Besluit van 20 December 1921 (P.B. No. 83) werd de heffing en invordering geregeld van het schoolgeld voor de leerlingen der openbare scholen in Curaçao.

De grondslag der heffing is het bedrag waarvoor de ouders, voogden of verzorgers der leerlingen in de inkomstenbelasting zijn aangeslagen.

Het schoolgeld is verschuldigd door de ouders, voogden of verzorgers.

Vrijgesteld van de betaling van schoolgeld voor de leerlingen, geplaatst op een school voor lager onderwijs, zijn de ouders, voogden of verzorgers, die niet in de inkomstenbelasting zijn aangeslagen.

Naar gelang de ouders, voogden of verzorgers van leerlingen, toegelaten tot een openbare school voor meer uitgebreid lager onderwijs op Curaçao dan wel tot een openbare school voor lager onderwijs in de Kolonie, in de inkomstenbelasting zijn aangeslagen naar een inkomen van:

$1^{\circ}$ minder dan $f$ 1500.- (eerste klasse van heffing)

$2^{\circ} f$ 1500.- of meer, doch minder dan $f 3.000$. - (tweede klasse van heffing)

$3^{\circ} f$ 3.000.- of meer, doch minder dan $f$ 4.500.- (derde klasse van heffing)

$4^{\circ} f$ 4.500.- of meer, doch minder dan $f 6.000$. - (vierde klasse van heffing)

$5^{\circ} f 6.000$. - of meer, (vijfde klasse van heffing).

bedraagt het jaarlijks verschuldigde schoolgeld.

$A$ bij plaatsing in het vierde of een lager leerjaar

\begin{tabular}{|c|c|c|c|c|c|c|}
\hline \multirow{2}{*}{$\begin{array}{l}\text { Klasse } \\
\text { van } \\
\text { heffing }\end{array}$} & \multicolumn{2}{|c|}{$\begin{array}{l}\text { Voor het eerste kind. } \\
\text { Op een school voor }\end{array}$} & \multicolumn{2}{|c|}{$\begin{array}{l}\text { Voor het tweede kind } \\
\text { Op een school voor }\end{array}$} & \multicolumn{2}{|c|}{$\begin{array}{l}\text { Voor het derde kind } \\
\text { Op een school voor }\end{array}$} \\
\hline & & 1.o. & m.u.l.o. & & m.u.l.o. & 1.o. \\
\hline le & 30.- & $f 3 .-$ & 24.- & 1.80 & $f$ 18.- & 1.20 \\
\hline $2 \mathrm{e}$ & 42.- & 6.- & 33.- & 3.60 & 24.- & 2.40 \\
\hline $3 e$ & 54.- & 9.- & $42 .-$ & 5.40 & 30.- & 3.60 \\
\hline $4 e$ & 72.- & 12.- & 54.- & 7.20 & $42 .-$ & 4.80 \\
\hline $5 e$ & 90.- & 15.- & 72.- & 9.- & 54.- & 6. - \\
\hline
\end{tabular}


$B$ bij plaatsing in het vijfde of een hooger leerjaar

\begin{tabular}{|c|c|c|c|c|}
\hline le & 42.- & $f$ 4.80|f 33.- & $f 3.60$ & 24.- \\
\hline $2 e$ & 54.- & 9.60 42.- & 7.20 & 30.- \\
\hline & 72.- & 14.40 & 10.80 & 42.- \\
\hline & 96.- & 72.- & 14.40 & 54.- \\
\hline & 120.- & 24.-90.- & 18.- & 66.- \\
\hline
\end{tabular}

$C$ bij plaatsing op een school voor lager onderwijs buiten het stadsdistrict van een der eilanden in de Kolonie

\begin{tabular}{c|c|c|c}
\hline \hline $\begin{array}{c}\text { Klasse } \\
\text { van } \\
\text { heffing }\end{array}$ & $\begin{array}{c}\text { Voor het eerste } \\
\text { kind }\end{array}$ & $\begin{array}{c}\text { Voor het tweede } \\
\text { kind }\end{array}$ & $\begin{array}{c}\text { Voor het derde en } \\
\text { ieder volgend kind }\end{array}$ \\
\hline & $f 1.50$ & $f 0.90$ & $f 0.60$ \\
$1 \mathrm{e}$ & $3 .-$ & 1.80 & 1.20 \\
$\mathrm{e}$ & 4.50 & 2.70 & 1.80 \\
$3 \mathrm{e}$ & $6 .-$ & 3.60 & 2.40 \\
$4 \mathrm{e}$ & 7.50 & 4.50 & $3 .-$ \\
$5 \mathrm{e}$ & & &
\end{tabular}

Voor de toepassing van voormelde tarieven maakt het geen verschil of de kinderen tot één gezin behoorende, een of beide openbare scholen voor meer uitgebreid lager onderwijs, dan wel één of meer openbare scholen voor lager onderwijs op een der eilanden, in of buiten het stadsdistrict bezoeken en wordt het oudste als het eerste kind beschouwd.

Ouders, voogden of verzorgers van leerlingen, toegelaten tot een openbare school voor meer uitgebreid lager onderwijs op Curaçao, die wegens te gering inkomen niet in de inkomsten belasting zijn aangeslagen, worden voor het betalen van schoolgeld in de eerste klasse van heffing gerangschikt.

Tengevolge van eene wijziging van het Regeerings Reglement werden het bijzonder en het openbaar onderwijs gelijkgesteld. De gelijkstelling trad in werking op 1 Juli 1935 tegelijk met de Verordening van 27 Februari 1935 (P.B. No. 44) in zake de uitkeeringen uit 's Lands kas aan de besturen der bijzondere scholen voor onderwijs. Krachtens het bepaalde bij art. 104 der Verordening van 27 Februari 1935 (P.B. No. 43) moeten de besturen der bijzondere scholen voor onderwijs de geheven schoolgelden in 's Lands kas storten. 
De opbrengst der schoolgelden heeft bedragen in:

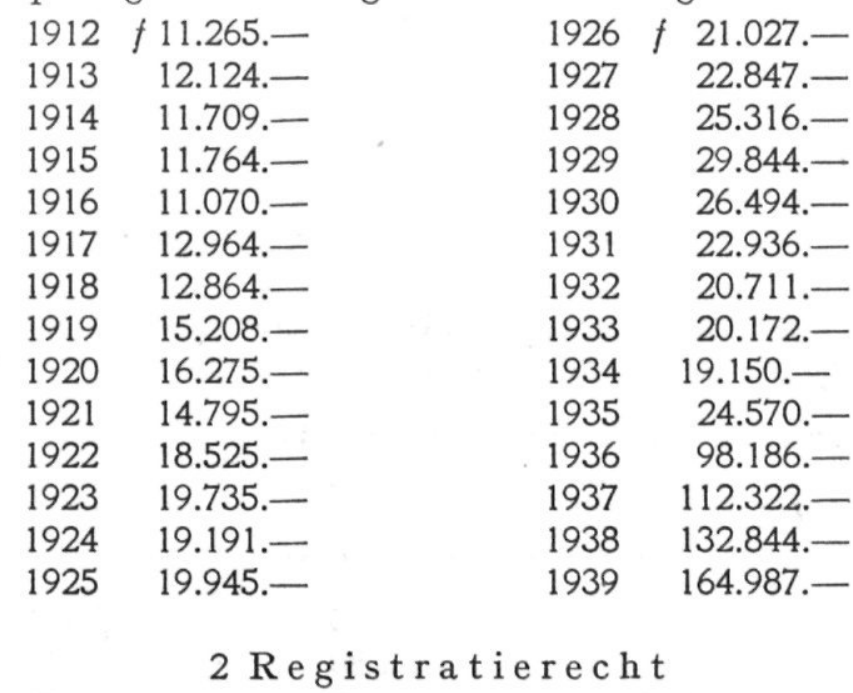

De „Registratieverordening 1908” (P.B. 1908 No. 47) onderging, voor zooveel betreft het recht, geen verandering.

Het registratierecht heeft opgebracht in:

\begin{tabular}{|c|c|c|c|}
\hline 1912 & 700.- & 1926 & $f 1.463 .-$ \\
\hline 1913 & 842.- & 1927 & 1.648.- \\
\hline 1914 & 703.- & 1928 & 1.699.— \\
\hline 1915 & 709.- & 1929 & 2.432. - \\
\hline 1916 & 673.- & 1930 & 2.923. - \\
\hline 1917 & 864.- & 1931 & 2.794.— \\
\hline 1918 & $712 .-$ & 1932 & 2.139. \\
\hline 1919 & 959.- & 1933 & 1.804. \\
\hline 1920 & 1.287.- & 1934 & 1.890. \\
\hline 1921 & $1.084 .-$ & 1935 & 2.176.- \\
\hline 1922 & 1.233.- & 1936 & 1.957.- \\
\hline 1923 & $1.116 .-$ & 1937 & 2.243.- \\
\hline 1924 & 1.090.- & 1938 & 2.513 . \\
\hline 1925 & 1.378.- & 1939 & 3.133.- \\
\hline
\end{tabular}

3 Uitvoerrecht van mijnproducten

Het uitvoerrecht op in of boven den grond op het eiland Klein-Curaçao aanwezige en aldaar gewonnen meststoffen werd bij de Verordening van 14 October 1912 (P.B. No. 50) verhoogd van 4 tot $6 \%$ van de waarde, wanneer het phosphaat een hooger gehalte dan $65 \%$ heeft. 
Voor die aanwezig op Aruba en aldaar gewonnen op het mijnveld in concessie bij de Aruba Phosphaat Maatschappij werd het recht bepaald op 3\% van de waarde.

Bij Verordening van 8 December 1922 (P.B. 1923 No. 30) werden de bepalingen omtrent de heffing bij uitvoer van metaalertsen, delfstoffen en door natuurvorming in of boven den grond aanwezige meststoffen, herzien.

Het uitvoerrecht op mijnproducten werd daarbij verhoogd van 4 tot $6 \%$ van de waarde.

Het uitvoerrecht heeft opgebracht in:

\begin{tabular}{|c|c|c|c|}
\hline 1912 & $f$ 13.029. & 1922 & $f$ 73.827.- \\
\hline 1913 & 11.864.- & 1923 & 98.250.- \\
\hline 1914 & 11.209.- & 1924 & 119.775.- \\
\hline 1915 & 18.830.- & 1925 & 88.693.- \\
\hline 1916 & 7.851.- & 1926 & 126.685.- \\
\hline 1917 & 2.813.- & 1927 & 129.444.- \\
\hline 1918 & $\begin{array}{l}\text { wegens den oorlog werd } \\
\text { de uitvoer stopgezet }\end{array}$ & 1928 & 135.966.- \\
\hline 1919 & 6.839.- & 1929 & 126.964.- \\
\hline 1920 & 77.382.- - - & 1930 & 85.621.- \\
\hline 1921 & 71.530.- & 1931 & 73.595.- \\
\hline 1932 & 51.795.- & 1936 & 36.369. \\
\hline 1933 & 55.700.- & 1937 & 51.554. - \\
\hline 1934 & 55.599.- & 1938 & 51.692. - \\
\hline 1935 & 41.346.- & 1939 & 31.098. - \\
\hline
\end{tabular}

4 Uitvoerrecht van zout van St. Martin

De Verordening van 16 Juli 1908 (P.B. No. 39) betreffende het uitvoerrecht van zout van St. Martin werd bij die van 16 Maart 1931 (P.B. No. 23) ingetrokken.

Het uitvoerrecht heeft in de jaren 1912 t/m 1931 opgebracht, als volgt:

\begin{tabular}{|c|c|}
\hline 1912 & $f$ 388.- \\
\hline 1913 & 739.- \\
\hline 1914 & 1.171.- \\
\hline 1915 & 837.- \\
\hline 1916 & 678.- \\
\hline 1917 & 924.- \\
\hline 1918 & 1.815.- \\
\hline 1919 & 1.587.- \\
\hline 1920 & 2.422.- \\
\hline 1921 & 2.682 . \\
\hline
\end{tabular}

$\begin{array}{rr}1922 & f 2.199 .- \\ 1923 & 2.458 .- \\ 1924 & 2.169 .- \\ 1925 & 744 .- \\ 1926 & 1.782 .- \\ 1927 & 1.219 .- \\ 1928 & 1.389 .- \\ 1929 & 1.229 .- \\ 1930 & 1.355 .- \\ 1931 & 292 .-\end{array}$




\section{L o odsgelden}

Bij de ontwikkeling, die het verleenen ter zee gestadig onderging, was de wetgeving omtrent het loodswezen ten achteren geraakt en beantwoordde zij niet meer aan de toenmalige eischen van het verkeer, zoodat het noodig was de bestaande bepalingen omtrent de loodsgelden te herzien.

Deze herziening kwam tot stand bij de Verordening van 22 November 1917 (P.B. 1918 No. 24) en trad in werking op 8 Mei 1918; tegelijkertijd verviel de Verordening van 24 Januari 1908 (P.B. No. 5) betreffende de loodsgelden, zooals die werd gewijzigd bij de Verordening van 2 Januari 1915 (P.B. No. 1).

Van af gemelden datum bedraagt het loodsgeld:

\section{A S toomschepen en lichters}

$1^{\circ}$ voor het loodsen uit zee in de St. Annabaai of het Schottegat, of omgekeerd uit de St. Annabaai of het Schottegat naar zee, voor een stoomschip of een gesleepten lichter, met een brutoinhoud:

$$
\begin{aligned}
& \text { van beneden } 400 \text { tonnen van } 2.83 \mathrm{M}^{3} \text {. . . . } f \text { 15.- } \\
& \text {, } 400 \text { tot beneden } 800, \text {, } 2.83, \ldots \text {. . . } 27.50 \\
& \text { " } 800, \text { " } 1800 \text { " }, 2.83 \text { " } \\
& \text { " } 1800 \text { tonnen van } 2.83 \mathrm{M}^{3} \text { en daarboven . . . . . . } 37.50
\end{aligned}
$$

\section{B Z eilschepen}

$1^{\circ}$ voor het loodsen uit zee in de St. Annabaai of het Schottegat of omgekeerd uit de St. Annabaai of het Schottegat naar zee voor een zeilschip

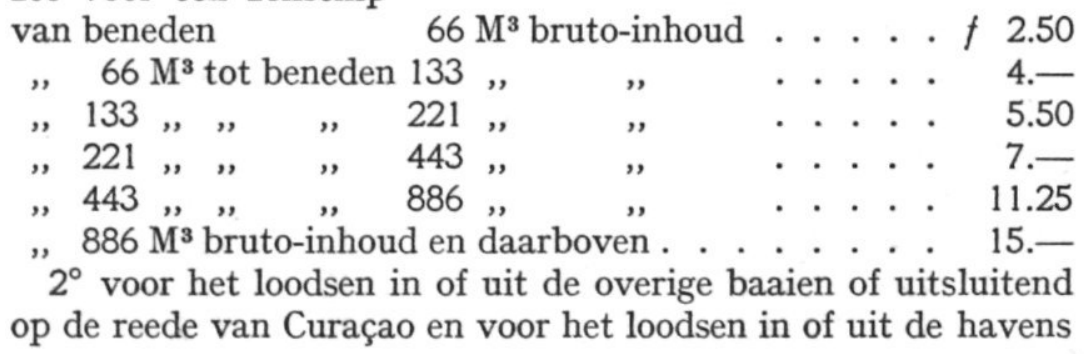


of baaien of op de reeden der overige eilanden van de Kolonie in de Paardenbaai op Aruba drie vierde, in alle andere gevallen de helft van het onder $\mathrm{B} 1^{\circ}$ bepaalde, naar de daar gemaakte onderscheidingen.

Voor vaartuigen, die de Kolonie aandoen om ruwe olie aan te brengen voor aldaar gevestigde raffinaderijen, bedraagt het loodsgeld de helft van de hierboven onder $\mathrm{A}$ en $\mathrm{B}$ vermelde bedragen, naar de daar gemaakte onderscheidingen.

In afwijking van de onder A en B hiervoren bedoeld vermelde tarieven bedraagt het loodsgeld voor oorlogsschepen:

$1^{\circ}$ voor het loodsen uit zee in de St. Annabaai of het Schottegat of omgekeerd uit de St. Annabaai of het Schottegat naar zee, een halve cent per ton waterverplaatsing;

$2^{\circ}$ voor het loodsen in of uit de overige baaien of uitsluitend op de reede van Curaçao en voor het loodsen in of uit de havens of baaien en op de reeden van de overige eilanden der Kolonie, een vierde cent per ton waterverplaatsing.

Voor een vaartuig, geen loods aan boord hebbende, maar door een schip waarop zich een loods bevindt, gesleept wordende, is eveneens het loodsgeld verschuldigd.

Overigens is voor de navolgende loodsdiensten als loodsgeld schuldig:

$1^{\circ}$ voor het loodsen uit zee in de St. Annabaai of het Schottegat naar zee, wanneer een en ander geschiedt tusschen een half uur nà zonsondergang en een half uur vóór zonsopgang.

een gelijk bedrag als hiervoren bepaald.

$2^{\circ}$ voor het verhalen van vaartuigen binnen de St. Annabaai of het Schottegat, uit de St. Annabaai naar het Schottegat of uit het Schottegat naar de St. Annabaai, wanneer dit geschiedt op verzoek of ten gerieve van den gezagvoerder of schipper: voor een vaartuig van $500 \mathrm{M}^{3}$ of daarboven . . . . . . f $25 .-$

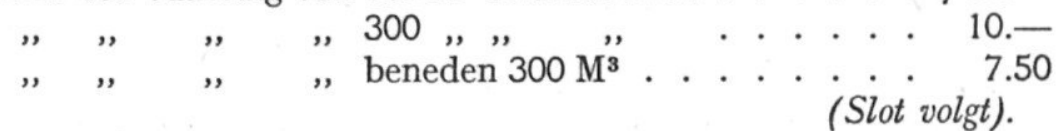

